\title{
Synthesis and Physicochemical Characterization of Pure Diammonium Phosphate from Industrial Fertilizer
}

\author{
M. Gargouri, ${ }^{* \dagger}$ C. Chtara, ${ }^{\ddagger}$ P. Charrock, ${ }^{\S}$ A. Nzihou, ${ }^{\perp}$ and H. El Feki ${ }^{\dagger}$ \\ ${ }^{\dagger}$ Laboratory of Materials Sciences and Environment, Science University of Sfax, 3010 Sfax, University of Sfax, Tunisia. \\ ${ }^{\ddagger}$ Chemical Group of Tunisia, Gabes \\ ${ }^{\S}$ LERISM, IUT P.Sabatier, Castres 81104, France \\ ${ }^{\perp}$ RAPSODEE, Ecole des Mines d'Albi-Carmaux, campus Jarlard, 81013, Albi, France
}

\begin{abstract}
Diammonium phosphate (DAP) is produced from industrial phosphoric acid that contains large amounts of anionic and cationic impurities ( $\mathrm{Co}, \mathrm{Cu}, \mathrm{Fe}, \mathrm{Mn}, \mathrm{Mo}, \mathrm{Ni}, \mathrm{Zn}, \mathrm{F}, \mathrm{As}, \mathrm{Al}, \mathrm{Hg}, \mathrm{Pb}$ and $\mathrm{Cd}$ ). Consequently all those impurities will be found in DAP. However, the industrial DAP obtained can be used as fertilizers, but cannot be used for some industrial application like pharmaceutics and cosmetics. After purification, the price of DAP is three times more expensive than the same product before purification. The procedure for purification of industrial DAP is a recrystallization, by using several mixtures of solvents. The physicochemical characterization of this fertilizer upstream and downstream from the purification, through spectroscopic analyses and chemical analyses, shows that recrystallization eliminates impurities. Purified DAP was obtained, the physicochemical properties of which are comparable to those of the pure commercial DAP (Fisher).
\end{abstract}

\section{INTRODUCTION}

Diammonium phosphate (DAP) is an important commercial fertilizer. The important water-soluble P fertilizers include monoammonium phosphate (MAP) and diammonium phosphate (DAP). ${ }^{1}$ The fertilizer is produced industrially in large quantities via the reaction between gaseous ammonia and green phosphoric acid. The reaction is exothermic; the equation for the neutralization reaction between ammonia and phosphoric acid is as follows: ${ }^{2}$

$$
2 \mathrm{NH}_{3}+\mathrm{H}_{3} \mathrm{PO}_{4} \rightarrow\left(\mathrm{NH}_{4}\right)_{2} \mathrm{HPO}_{4}
$$

When the molar ratio (MR) of ammonia to phosphoric acid is 2, DAP is formed. ${ }^{2}$ The phosphoric acid used in producing DAP can be crude unpurified acid obtained by dissolving phosphate rock with sulfuric acid. In this case, crude DAP results, which may be adequate for some applications. However phosphate rock may contain heavy metals and these can be transferred to the fertilizer, and further to crops.

Two options are available to produce purified DAP: (1) use purified phosphoric acid; (2) purify the DAP. For producing industrial purified diammonium phosphate from wet process phosphoric acid, it is necessary to purify the phosphoric acid in advance according to a process of extracting phosphoric acid from wet process phosphoric acid according to a solvent process,

Table 1. Chemical Compositions of the DAP Upstream and Downstream from the Recrystallization

\begin{tabular}{|lccccc|} 
& $\mathrm{P}_{2} \mathrm{O}_{5}$ & \multicolumn{1}{c}{$\mathrm{N}$} & $\mathrm{H}_{2} \mathrm{O}$ & $\mathrm{MR}$ & \\
\multicolumn{1}{c}{ samples } & $(\mathrm{wt}) \%$ & $(\mathrm{wt}) \%$ & $(\mathrm{wt}) \%$ & $(\mathrm{~N} / \mathrm{P})$ & $\mathrm{pH}$ \\
\hline plant DAP & 46.05 & 17.65 & 1.50 & 1.94 & 7.6 \\
plant DAP recrystallized & 49 & 18 & 1.68 & 1.86 & 7.9
\end{tabular}

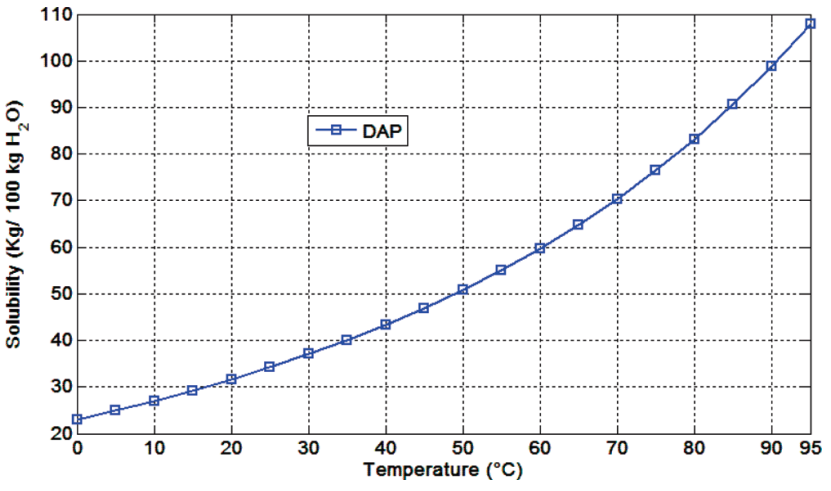

Figure 1. Curve solubility of recrystallized DAP.

followed by reacting ammonia with the resulting extract to obtain diammonium phosphate containing a small amount of impurities. However, this extraction process cannot be regarded as an industrially advantageous process owing to its complicated steps. ${ }^{3}$

Our work began with the purification of monoammonium phosphate (MAP) from industrial fertilizer, and the results are very encouraging. ${ }^{4}$ This prompted us to pursue this study on another product of the same family, DAP.

In the present work, we are interested in eliminating impurities from industrial DAP. We present here the physicochemical characterization of DAP fertilizer upstream and downstream of the purification process, with an aim to determine the performance 
Table 2. Determination the Impurity Present in the DAP Upstream and Downstream from the Recrystallization ${ }^{a}$

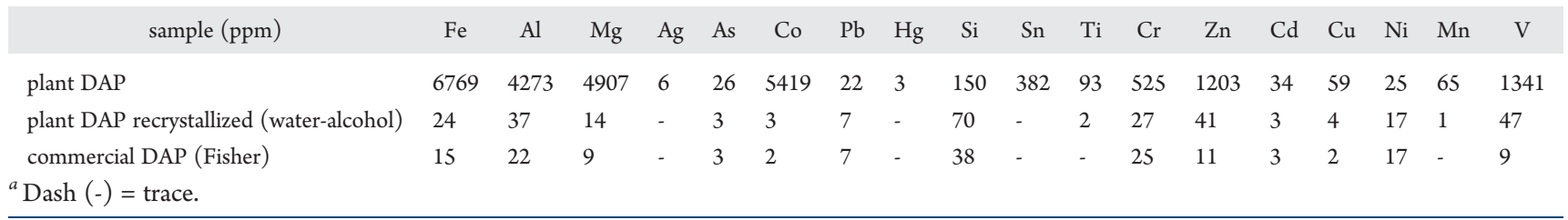

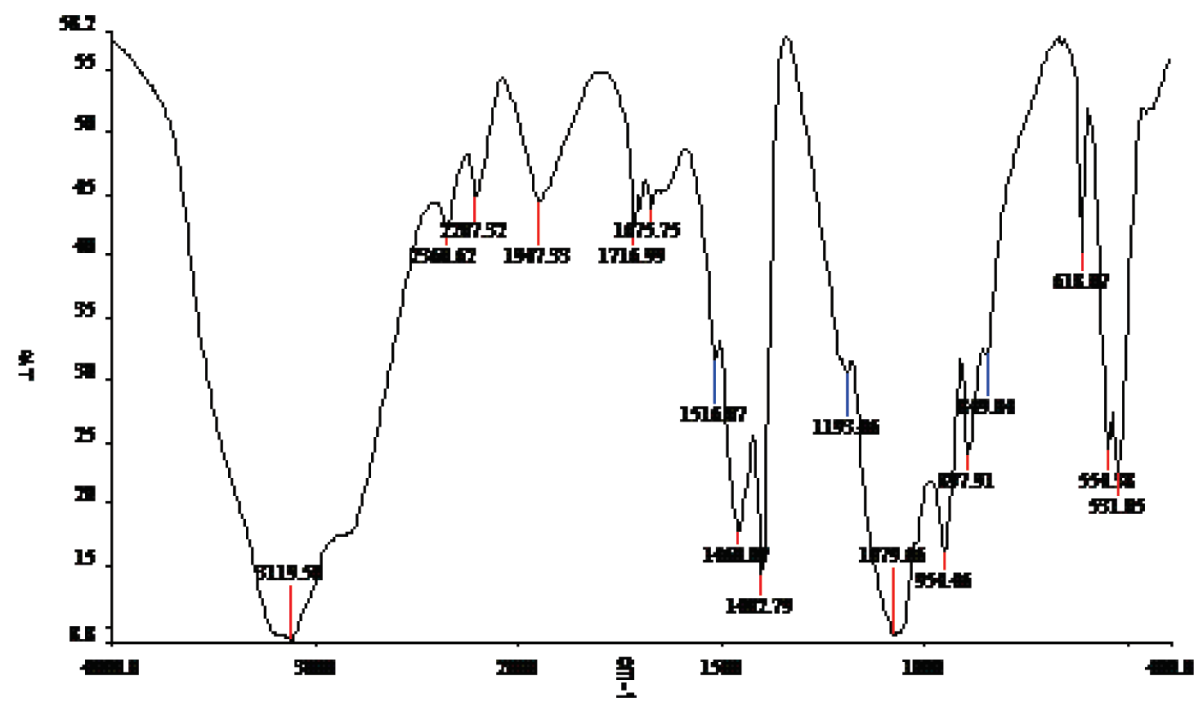

Figure 2. The analysis by means of IR of the industrial DAP upstream from the recrystallization.

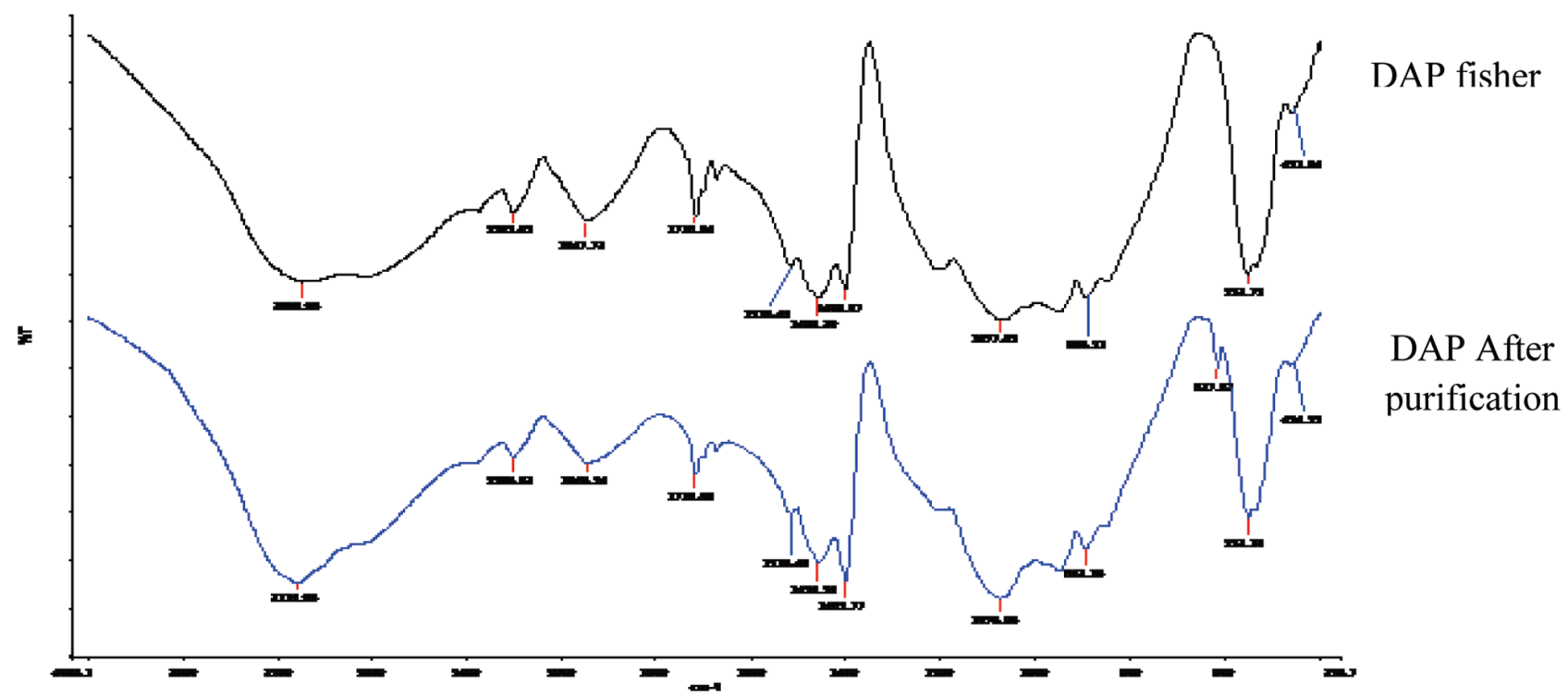

Figure 3. The analysis by means of IR of the industrial DAP downstream from the recrystallization and pure commercial DAP (Fisher).

of recrystallization. We also compare the recrystallized DAP to the commercial DAP (Fisher).

\section{EXPERIMENTAL SECTION}

2.1. Recrystallization. Crystallization experiments of DAP (fertilizer synthesized in industry from Tunisia) were carried between 273 and $400 \mathrm{~K}$ and at $400 \mathrm{rpm}$ stirring rate. The suspension was dissolved in mixed solvent ( $70 \%$ water-30\% alcohol). After that we add a quantity of charcoal in the solution. The suspension was filtered, and the solution was cooled to $273 \mathrm{~K}$, whereupon crystals appeared. We recrystallized the DAP using a mixture of solvent, water, and alcohol. Impurities were analyzed by inductively coupled plasma-optical emission spectroscopy (ICPOES). 


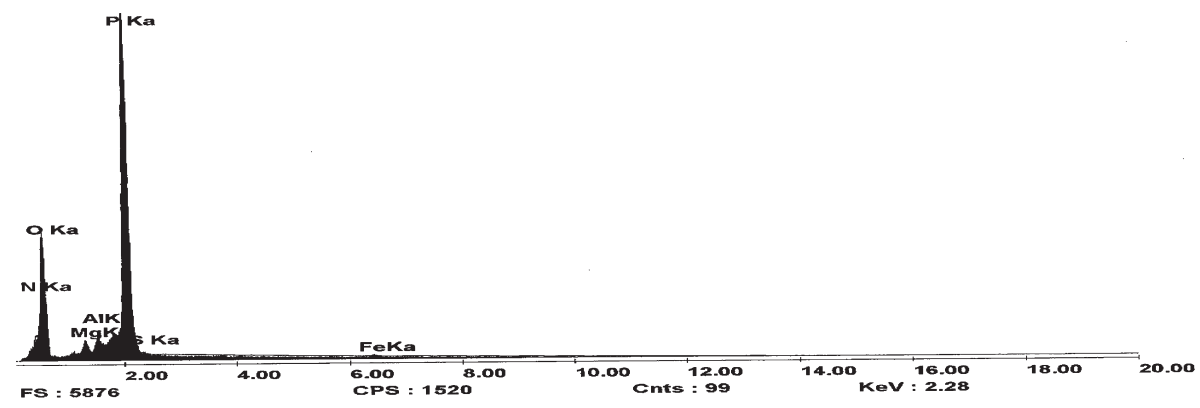

a. upstream from the recrystallization

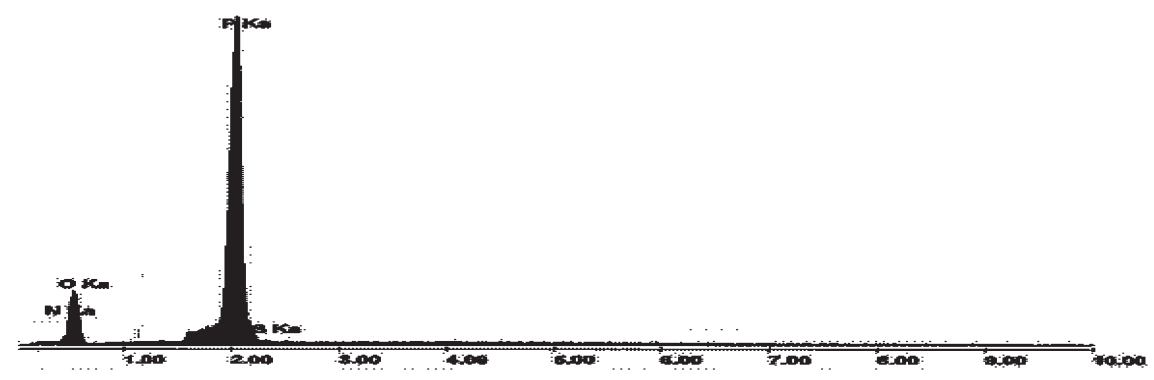

b. downstream from the recrystallization

Figure 4. The analysis by MEB of the industrial DAP upstream and downstream from the recrystallization.

Table 3. The Wavelength of the Vibration Mode of DAP Upstream (ur) and Downstream (dr) from the Recrystallization and Pure Commercial DAP (Fisher)

\begin{tabular}{llrcc}
\multicolumn{1}{c}{$\begin{array}{c}\text { band limit of } \\
\text { bands }\end{array}$} & & & pure commercial \\
absorption $\left(\mathrm{cm}^{-1}\right)^{8,9}$ & DAP (ur) & DAP (dr) & DAP (Fisher) \\
$\mathrm{PO}_{4}{ }^{3-}$ & $v_{1}: 1000-800$ & 954 & 886 & 893 \\
& $v_{2}: 500-300$ & 531 & 454 & 451 \\
& $v_{3}: 1200-1000$ & 1097 & 1076 & 1077 \\
& $v_{4}: 650-500$ & 618 & 553 & 553 \\
$\mathrm{NH}_{3}$ & $\partial_{\mathrm{a}}: 1600-1575$ & 1516 & 1516 & 1516 \\
& $\partial_{\mathrm{s}}: 1500-1300$ & 1400 & 1403 & 1402 \\
$\mathrm{NH}_{4}^{+}$ & $v_{\mathrm{NH}}: 3300-3030$ & 3119 & 3119 & 3099 \\
$\mathrm{H}_{2} \mathrm{O}$ & $v_{\mathrm{OH}}: 3600-3100$ & 3119 & 3119 & 3099 \\
\hline
\end{tabular}

2.2. Analytical and Testing Methods. $\mathrm{P}_{2} \mathrm{O}_{5}$ content in the solution is determined gravimetrically. The molar rapport of ammonia to phosphoric acid (MR) was obtained by titration with standard $0.5 \mathrm{M} \mathrm{NaOH}$ and $0.5 \mathrm{M} \mathrm{HCl}$ solutions. The amount of $\mathrm{HCl}$ and $\mathrm{NaOH}$ added was used to calculate the MR that is equal to 2 (volume of $\mathrm{NaOH}$ /volume of $\mathrm{HCl}$ ), according to the method described in ref 5. A pH Meter was employed to measure the $\mathrm{pH}$ values of slurries. $\mathrm{N}$ content in the solutions was determined by the Kejdahl method. Melting points were determined with a METTLER FP62 that uses a capillary tube. The curve solubility was determined following a standard procedure described by Mullin. ${ }^{6}$ IR spectra were determined by a FTIR system spectrum BX Perkin-Elmer spectrometer. The analysis by scanning electron microscope (SEM) is determined with a MEB Philips série XL 30. Data collection is realized by using
KappaCCD Server Software (Nonius, 2004); program(s) used to solve structure are SHELXS97. The spectra of X-ray powder diffraction (XRPD) is determined by a Seifert 3000. T.T. spectrometer.

\section{RESULTS AND DISCUSSION}

The principal chemical compositions of the DAP upstream and downstream from the recrystallization are presented in Table 1. After purification, the $\% \mathrm{P}_{2} \mathrm{O}_{5}$ and $\% \mathrm{~N}$ were increased while keeping the molar ratio (MR) range between 1.8 and 2.0. Also, after purification the percentage of $\mathrm{H}_{2} \mathrm{O}$ and value of $\mathrm{pH}$ are slightly changed but in the various ranges stated. There is $25 \%$ of impurities by weight in the crude industrial DAP.

Diammonium phosphate granules contain various compounds $(\mathrm{Ca}, \mathrm{Mg})\left(\mathrm{NH}_{4}\right)(\mathrm{Fe}, \mathrm{Al})\left(\mathrm{PO}_{4}\right)(\mathrm{F}, \mathrm{OH}) \mathrm{H}_{2} \mathrm{O}$ that are insoluble in water and can comprise up to $10 \%$ of the total $\mathrm{P}$ content of fertilizers. ${ }^{7}$ The DAP contains toxic elements such as $(\mathrm{Cd}, \mathrm{Zn}, \mathrm{Cu}$, and $\mathrm{Ni}$ ) which are toxic for plants and have the potential for adverse effects on human health due to the transfer of metals from soils to food corps. Thus, it is important to eliminate or reduce these toxic elements in DAP. The analysis of the DAP after purification is given in Table 2 and shows that the quantity of impurity decreases. The results are comparable to those of the commercial DAP (Fisher).

After recrystallization, the melting point was found to be $194^{\circ} \mathrm{C}$, close to the one of laboratory grade DAP $\left(196^{\circ} \mathrm{C}\right)$.

The curve solubility of recrystallized DAP, that was determined following a standard procedure described by Mullin, ${ }^{6}$ is shown in Figure1. The solubility of a solute is most conveniently stated as the parts by weight per part (or 100 parts) by weight of solvent.

The analysis by means of IR of the DAP before and after recrystallization is presented in Figures 2 and 3. 
Table 4. Crystal Data Details and Structure Refinement of the Plant DAP Downstream from the Recrystallization and Commercially Pure DAP

\begin{tabular}{|c|c|c|}
\hline & $\begin{array}{l}\text { DAP } \\
\text { recrystallized }\end{array}$ & $\begin{array}{l}\text { pure commercial } \\
\text { DAP (Fisher) }\end{array}$ \\
\hline \multicolumn{3}{|c|}{ I. Crystal Data } \\
\hline formula & $\left(\mathrm{NH}_{4}\right)_{2} \mathrm{HPO}_{4}$ & $\left(\mathrm{NH}_{4}\right)_{2} \mathrm{HPO}_{4}$ \\
\hline formula weight $(\mathrm{g} / \mathrm{mol})$ & 132.06 & 132.06 \\
\hline system & monoclinic & monoclinic \\
\hline space group & $P 21 / c$ & $P 21 / c$ \\
\hline$a(\AA)$ & $10.781(2)$ & $10.729(5)$ \\
\hline$b(\AA)$ & $6.771(2)$ & $6.682(5)$ \\
\hline$c(\AA)$ & $8.047(2)$ & $8.009(5)$ \\
\hline$\square$ & $109.72(2)$ & $109.670(5)$ \\
\hline$V\left(\AA^{3}\right)$ & $448.1(2)$ & $540.7(6)$ \\
\hline$Z$ & 4 & 4 \\
\hline$\rho_{\text {cal }}\left(\mathrm{g} \mathrm{cm}^{-3}\right)$ & 1.600 & 1.622 \\
\hline$F(000)$ & 280 & 332 \\
\hline$\mu(\mathrm{Mo} \mathrm{K} \alpha)\left(\mathrm{mm}^{-1}\right)$ & 0.427 & 0.433 \\
\hline crystal color & colorless & colorless \\
\hline \multicolumn{3}{|c|}{ II. Intensity Measurements } \\
\hline temperature $(\mathrm{K})$ & $293(2)$ & $293(2)$ \\
\hline wavelength $\mathrm{Mo} \mathrm{K} \alpha(\AA)$ & 0.71073 & 0.71073 \\
\hline \multicolumn{3}{|l|}{ measurement area: } \\
\hline$h$ & $-13<h<13$ & $-12<h<12$ \\
\hline$k$ & $-1<k<8$ & $-7<k<7$ \\
\hline$l$ & $-10<l<7$ & $-9<l<9$ \\
\hline \multicolumn{3}{|c|}{ III. Structure Determination } \\
\hline $\begin{array}{l}\text { unique reflections included with } \\
\qquad I>2 \sigma(I)\end{array}$ & 1124 & 765 \\
\hline refined parameters & 100 & 101 \\
\hline unweighted agreement factor $R_{1}{ }^{a}$ & 0.0231 & 0.0262 \\
\hline weighted agreement factor $R w_{2}{ }^{a}$ & 0.0660 & 0.0783 \\
\hline \multicolumn{3}{|c|}{$\begin{array}{l}{ }^{a} R \text { values are defined as } R_{1}=\Sigma|| F_{\mathrm{o}}|-| F_{\mathrm{c}}|| / \Sigma\left|F_{\mathrm{o}}\right| \text { and } R w_{2}=\left[\Sigma w\left(F_{\mathrm{o}}{ }^{2}-\right.\right. \\
\left.\left.F_{\mathrm{c}}{ }^{2}\right)^{2} / \Sigma w\left(F_{\mathrm{o}}{ }^{2}\right)^{2}\right]^{1 / 2} \text { where } w^{-1}=\left[\sigma^{2}\left(F_{\mathrm{o}}{ }^{2}\right)+(0.0442 P)^{2}+2.4726 P\right] \\
\text { and } P=\left(F_{\mathrm{o}}{ }^{2}+2 F_{\mathrm{c}}{ }^{2}\right) / 3 \text {. }\end{array}$} \\
\hline
\end{tabular}

The characteristic wavelengths of the vibration modes of DAP are illustrated in Table 3, which shows the presence of the four modes of vibrations ascribed to $\mathrm{PO}_{4}{ }^{3-}$ observed at about 444 , 539,917 , and $1110 \mathrm{~cm}^{-1}$, the vibrations of ammonia observed about $1400 \mathrm{~cm}^{-1}$, and a wide band attributed to $\mathrm{H}_{2} \mathrm{O}$ and $\mathrm{NH}_{4}{ }^{+}$ stretching modes observed around $3137 \mathrm{~cm}^{-1}$.

In addition, the analysis by sweeping electron microscope (MEB) of the industrial DAP after recrystallization, showed that the elements of aluminum, magnesium, and copper are eliminated, and the quantity of sulfur was decreased (Figure 4).

The crystal structure of the recrystallized diammonium phosphate $\left(\mathrm{NH}_{4}\right)_{2} \mathrm{HPO}_{4}$ has been determined by X-ray single crystal analysis at room temperature. The space group is $P 21 / c^{10}$ with lattice parameter $a=10.781$ (2) $\AA, b=6.771(2) \AA, c=8.047(2) \AA$, and $Z=4$. The refinement converged to $R_{1}=0.0231$ and $R_{\mathrm{W} 2}=$ 0.0660. The analysis by X-ray diffraction showed that the purification of the DAP did not change the crystalline system (monoclinic). Crystal data details and structure refinement are given in Table 4 and show that the crystallographic parameters of

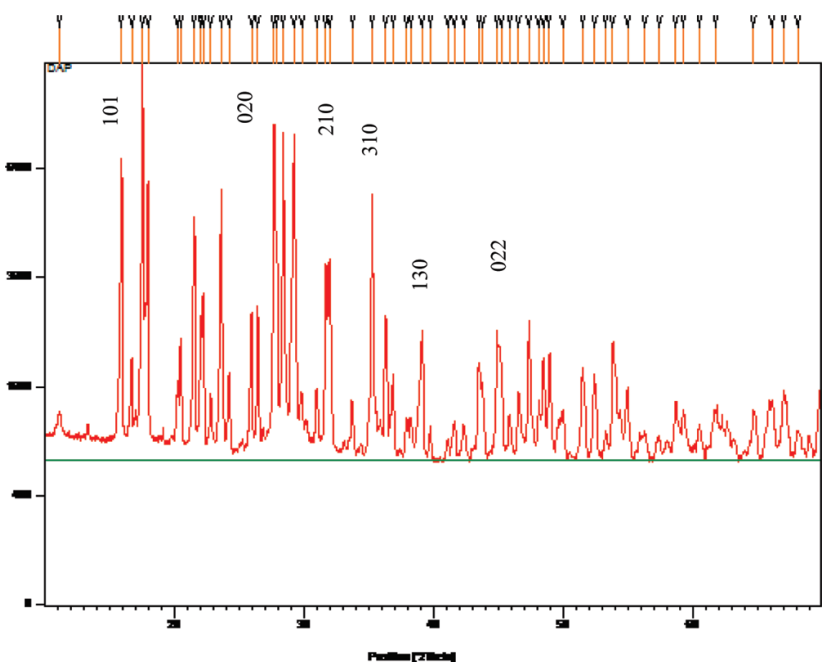

Figure 5. The analysis by XRPD of the industrial DAP.

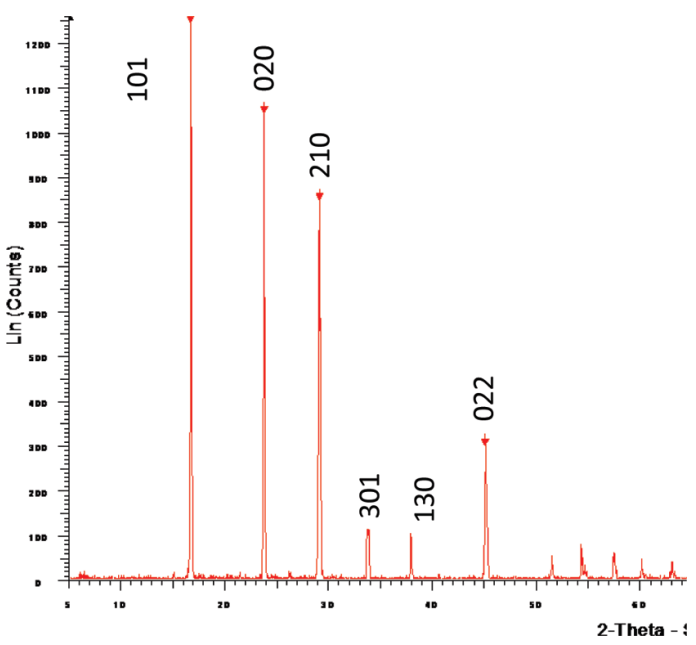

Figure 6. The analysis by XRPD of the industrial DAP downstream from the recystallization.

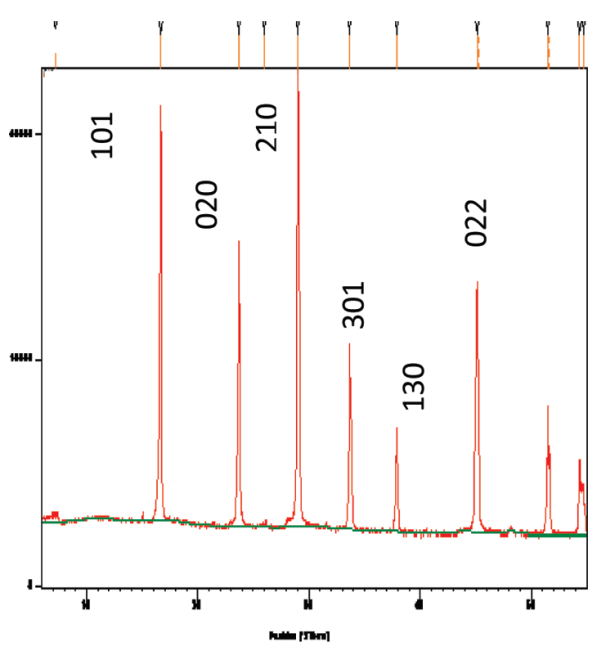

Figure 7. The analysis by XRPD of the pure commercial DAP (Fisher). 
recrystallized DAP are close to the pure DAP (Fisher), which justifies the performance of the recrystallization.

In addition, the analysis by X-ray powder of industrial DAP downstream of the purification (Figure 6) shows an elimination of the impurities that were found upstream of the purification (Figure 5), and we got a good crystalline product that resembles the pure commercial DAP (Fisher) (Figure 7).

\section{CONCLUSION}

The long-continued application of impure DAP can redistribute and elevate heavy metal concentrations in soils. The redistribution of heavy metals can adversely affect water resources and endanger the health of surrounding ecosystems and human populations. Thus, it is important to eliminate the different toxic elements present in the fertilizer in order to prevent transfer to plants and humans, in this case with the use of purified fertilizers in biological agriculture. On the other hand, you can also use the purified product in the pharmaceutics and cosmetic industries.

After purification, the $\% \mathrm{P}_{2} \mathrm{O}_{5}$ and $\% \mathrm{~N}$ increased, while the molar ratio (MR) remained between 1.8 and 2.00 and the products obtained contained $1.5-2 \% \mathrm{H}_{2} \mathrm{O}$ and had a $\mathrm{pH}$ value of $7-8$. The analysis by $\mathrm{X}$-ray diffraction showed that the purification of the plant DAP did not change the crystalline system (monoclinic).

The physicochemical characterization of the industrial DAP downstream of the purification, through spectroscopic analyses and chemical analyses, showed that we obtained purified DAP whose physicochemical properties are comparable with those of the pure commercial DAP (Fisher).

\section{AUTHOR INFORMATION}

\section{Corresponding Author}

*E-mail: gargouri1412@yahoo.fr.

\section{ACKNOWLEDGMENT}

The authors thank Dr. A. Driss from the University of Tunis, Tunisia, for his valuable collaboration.

\section{REFERENCES}

(1) Duraisamy, V. P. Role of inorganic and organic soil amendments. Aust. J. Soil Res. 2005.

(2) Campbell, G. R.; Leong, Y. K.; Berndt, C. C.; Liow, J. L. Ammonium phosphate slurry rheology and particle properties The influence of $\mathrm{Fe}(\mathrm{III})$ and $\mathrm{Al}(\mathrm{III})$ impurities, solid concentration, and degree of neutralization. Ind. Eng. Chem. Res. 2006, 61, 5856-5866.

(3) Akiyama, A. Studies on chemical fertilizers. K.K. Nissin Syuppan 1976.

(4) Gargouri, M.; Chtara, C.; Charock, P.; Nzihou, A.; Elfeki, H. Synthesis and physicochemical characterization of pure monoammonium phosphate (MAP) from industrial fertilizer. J. Chem. Chem. Eng. 2010, 49,

(5) Shengwei, Tang; Hui, Guo; Jiankang, ying; Bin., Liang Physicolchemical propreties of acidic ammonium phosphate slurries. Ind. Eng. Chem. Res. 2004, 43, 3199.

(6) Mullin, J. Crystallization; Butterworth-Heinemann : Oxford, GB, 2001.

(7) Gilkes, R. J.; Mangano, P. Poorly soluble iron-aluminium phosphates in ammonium phosphate fertilizers: Their nature and availability to plants. Aust. J. Soil Res. 1983, 21, 183-194.
(8) Nakamoto, K. Infrared and Raman Spectra of Inorganic and Coordination Compounds; Wiley: New York, 1984.

(9) Parker, F. S. Application of IR Spectroscopy in Biochemistry, Biology and Medicine; Hilger, A., Ed.; Plenum Press: New York, 1971.

(10) Khan, A. A.; Roux, J. P.; James, W. J. The crystal structure of diammonium phosphate, $\left(\mathrm{NH}_{4}\right)_{2} \mathrm{HPO}_{4}$. Acta Crystallogr., Sect. B 1972, $28,2065-2069$. 